\title{
The Impact of Online Quizzes on Student Success
}

\author{
https://doi.org/10.3991/ijet.v16i11.21679 \\ László Bognár \\ University of Dunaújváros, Dunaújváros, Hungary \\ Tibor Fauszt $\left({ }^{(x)}\right.$ \\ Budapest Business School University of Applied Sciences, \\ Budapest, Hungary \\ fauszt.tibor@uni-bge.hu \\ Mariann Váraljai \\ University of Dunaújváros, Dunaújváros, Hungary
}

\begin{abstract}
In today's modern world, the pace of technological development can be considered exponential. Education must constantly adapt to this dynamic development. It must be able to innovate, to use modern tools and methods that are effectively integrated into the learning process. Education should provide an appropriate learning environment to meet changing needs, one way of which is e-learning. This environment can be an excellent support for the learning process; however, it will hardly be effective without developing the right student learning attitude. The e-learning environment gives freedom and independence to the individual, at the same time. For the learner's individual endeavor to be successfully completed as expected, control and continuous feedback are needed.

One way to do this is through self-quizzing. Self-quizzes, divided into units, related to the learning material, with appropriate difficulty and amount, can help to understand and engrave the processed material, and thus improve the effectiveness of learning. Self-quizzes create the opportunity for immediate feedback, which is a very important feature of an e-learning environment. According to many scientific research, immediate feedback can greatly help maintain interest and motivation, and quizzes are suitable tools for this purpose.

In our research, we sought to answer the question of how the continuous, self-monitoring practice opportunity provided by online quizzes affects student achievement. In the case of an online course held at the University of Dunaújváros in 2019, we examined whether students who continuously perform self-quizzes will be more effective by the end of the learning process than their peers who are less receptive to independent self-quizzing. We also addressed the effect of the nature of time spent on self-reflexive quizzing on learning success.
\end{abstract}

Keywords - Student success, self-quizzing, online learning, e-learning 


\section{Introduction}

Numerous research address learning in an electronic environment and the factors that affect learning effectiveness. Factors influencing efficiency can be age, prior knowledge, or experience in e-learning, etc. [3], [20], [15], [13], [5.], [25], [10], [1], [19]. This environment promotes flexibility, giving the individual more freedom in the learning process [8], [17], [26], [4], [11]. However, in addition to the benefits, it has also been found that for several reasons, dropouts in courses created in this environment are very high [12], [28], [27], [22]. Therefore, maintaining attention and motivation in an e-learning course is a major challenge. It is necessary to incorporate learning resources that maintain interest, give feedback, praise, may reprimand, give advice, i.e., are interactive and measure. This is only possible if we monitor the learning process and continuously measure student performance. In some LMS systems already have sophisticated, built-in tools for monitoring the learning process. An example is the Moodle Analytics system, in which students exposed to failure can be identified by building machine learning models based on student activity [21], [6], [7]. Another tool for monitoring the learning process and measuring effectiveness are the micro self-checking quizzes and topic-closing quizzes, which appear in many studies as e-learning resources [16]. Using them, student activity and progress can be measured, feedback can be given to the student, and motivation can be maintained. Finally, it can be the basis for measuring the final acquired knowledge.

In an e-learning environment, the role of quizzes in the evaluation phase is complex. Globally, one of the most frequently used method to provide feedback about whether the learner is move forward according to the set of educational goals or whether it is necessary to intervene to succeed. Quizzes are assessment methods with many benefits that can be used effectively at any stage of the learning process. [23]. The design of quizzes requires caution, as it can strongly influence students' attitude on learning as a result of experiencing of success or failure.

Self-monitoring testing is a learning characteristic of the behaviorism trend, in which the learner appears as an observer in the learning process. Any form of feedback, be it reward or punishment, plays an important role in this process. The use of self-tests and similar closed tasks typically proves to be most effective in exploratoryoriented students.

In Bloom's taxonomy, quizzes, as assessment methods, are located at the first and second levels, i.e., at the level of knowledge and understanding. Their significance lies in the fact that in the initial phase of the learning process it helps to transform the acquired experience into knowledge. However, feedback can be useful at all stages of the process, be it exploring prior knowledge, establish new knowledge, mid-term review, follow-up, or measuring learning effectiveness [24]. Well-structured and timed assessments can provide insights into student progress, provide dynamic and personalized assessments, measure immediately, reveal student thinking, and have many other benefits [18], [24].

The importance of online self-tests in the validation process is also manifold. It can be a tool for positive reinforcement, with intervention it is a tool for clarification, with 
a self-reflexive function it can be self-monitoring, or it can also play a central role in the measurement and evaluation phase [9].

The positive effect of online self-tests can also be observed in psychological terms. The online learning environment gives the learner independence in space and time for self-realization [2], [14]. The more the learning environment adapts to the needs of the individual, the more they feel safe in it. So, the more confident and less tense they are involved in quizzing. A stress-free environment can also contribute to individual success by increasing concentration, helping to deepen thoughts, and there is no distraction that would distract and increase uncertainty.

\section{Course Description, Definition of Student Groups}

The study conducted among the students of the University of Dunaújváros in 2019 focused on the Moodle quiz-related activities of 57 full-time and 82 correspondence students. Log entries recorded by the system provided the data for the analysis. The system records all student activities as a log entries, which can be extracted from the Moodle database. The examined course was the Applied Statistics, with several topics (chapters) of different difficulty.

Each chapter contained 3 different types of learning resources in 5 different formats:

a. Text documents

- Lecture notes, learning material in PDF format

- Books, e-books of solved exercises.

b. Video materials

- Video, lecture video with teacher explanation

- Minitab, videos for problem solving with a statistical software.

c. Quizzes

- Quiz, "Learning the concepts quizzes" and "Chapter review quizzes" for selftesting.

The number of learning resources varied within each topic.

Of these, the research focused on Learning the concepts quizzes and Chapter review quizzes for self-checking. The studies did not include examinations of individual abilities.

The Learning the concepts quizzes contained only a few questions and did not take long to complete. These quizzes followed the lecture notes which were belonged to videos within a topic. The purpose of this kind of quizzes was to provide immediate feedback and draw attention to important parts. Each topic was closed by the Chapter review quizzes. Their purpose was to provide feedback to the student on their knowledge within a given topic. A common feature of both types of quizzes was that the system displayed the correct answers, so that the student could check the correct- 
ness of the answer to the question. Quizzes could be completed by students as many times as they wanted. The question bank was filled with many hundreds of questions from which the quiz questions were randomly selected. During the re-fillings, different questions were selected into the same quiz. Additional feature is that most of the questions were parameterized, so students could only answer the questions once they had mastered the underlying content. The huge question bank and the parameterized questions ensured that the students who just tried to learn the answers by heart could not achieve a good result.

Two separate courses were started for full-time and correspondence students, with the same content and format. However, their final grades came together in different ways. Full-time students had to complete 4 graded online tests during the semester (4x25 points), correspondence students had to complete 1 graded online test at the end of the semester to complete the course (1x100 points). The maximum score available in both cases was 100 points. In order to successfully complete the course, the total score of the students in both forms of education had to reach the minimum of 70 points.

In this study, both full-time and correspondence students were classified into three different groups based on their total score: Failed, whose score was below the minimum of 70 points, Satisfactory, who scored between 70 and 85, and a group of Excellent, who scored 85 points or more.

\section{$3 \quad$ Findings}

\subsection{Success and self-testing activity in time}

In Figure 1 the self-testing activity of the 3 groups in time can be seen. Time is on the horizontal axis and the Averages of Total Number of Quiz Attempts of students belonging to the 3 groups at a given time are plotted in the figure. On the time axis the start and end of the semester and the dates of the four graded tests scheduled between start and end are indicated with dashed lines.

Comparing the curves, one can see that there is a strong relationship between the self-testing activity and the type of group the students belong to. Students in the Excellent group quizzed 2-3 times more in the initial phase of the course than members of the Satisfactory group. This gap continues to grow over time. The same ratio can be seen when comparing the self-testing activities of members of the Satisfactory and Failed groups. Each group quizzed evenly throughout the semester, with no significant difference in their time dynamics. Each of the three lines representing self-testing activity shows a roughly linear characteristic.

Correspondence students began to quiz more intensively towards the end of the course (Figure 2). Roughly until half time, students quizzed few, and towards the end of the course, their self-testing activity increased significantly. This is especially true for the Failed and Satisfactory groups. The self-testing activity of the members of the Excellent group shows a more linear characteristic 


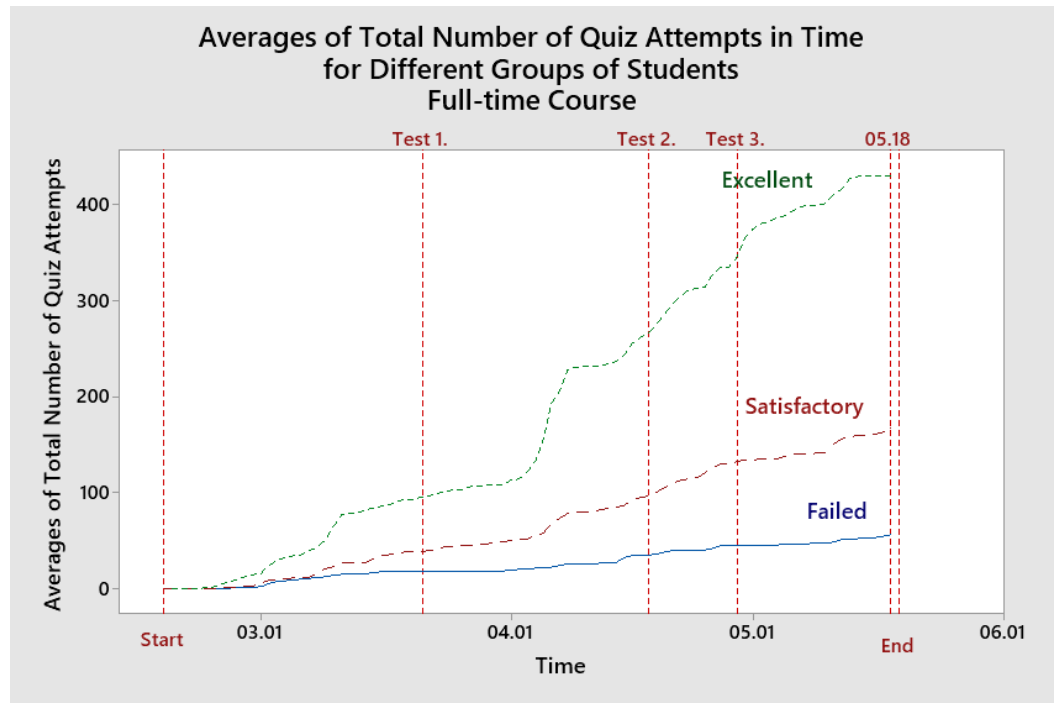

Fig. 1. The Averages of Total Number of Quiz Attempts of different groups of full-time students in time

The differences of the quizzing characteristic of the full time and correspondence students are likely to be found in the timing and frequency of graded tests, and differences in teaching methodologies. Correspondence students attended only a small number of contact lessons and there were no in-course graded tests. The in-course graded tests thus greatly helped to make the learning activity more even.

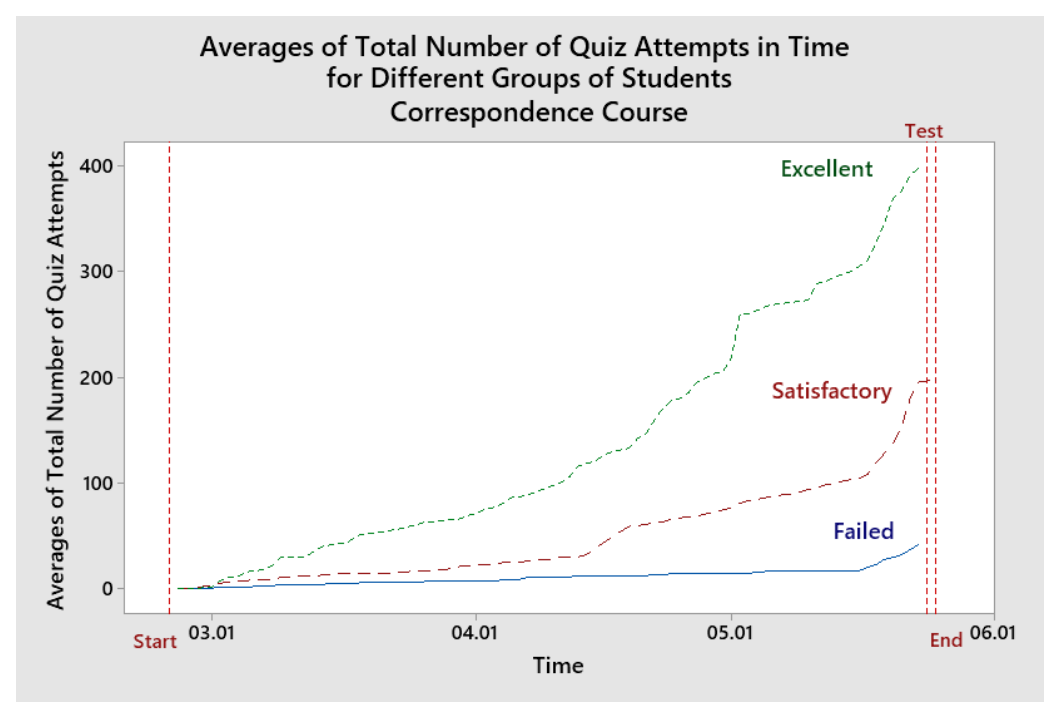

Fig. 2. The Averages of Total Number of Quiz Attempt in time for the three groups of correspondence students 
For a more in-depth analysis of students quizzing activity, the Average of Total Number of Quiz Attempts of full-time students was calculated for each period and group between the four tests separately. Each period shows the self-testing activity as a separate unit for that period. The green line marking the activities of the Excellent student group shows that the students started quizzing immediately and were quizzing with increasing intensity as they approached the graded tests dates. Their self-testing frequency is remarkably high. The other two groups, on the other hand, quizzed less, and the dynamic of timing of their activity cannot be said to be clearly constant. Prior to the graded tests their quizzing activity increased in the same way, but not to the same extent as that of the Excellent student group.

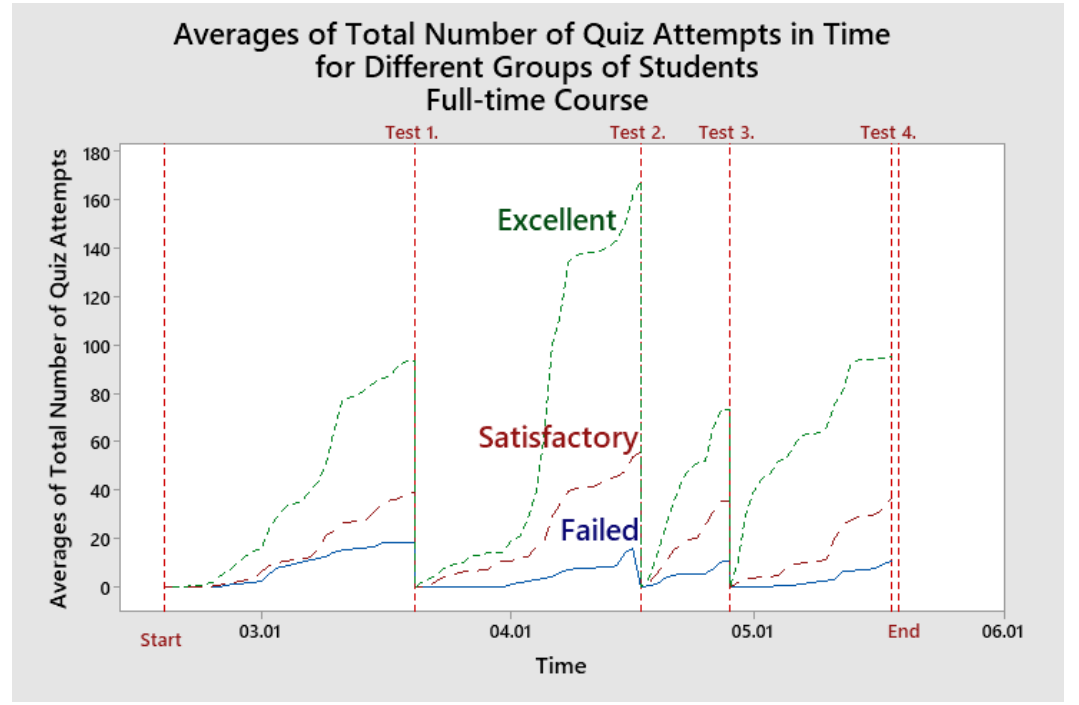

Fig. 3. Self-testing activity of full-time students between graded tests

The difference can also be clearly seen in the diagram showing the total self-testing activity of correspondence and full-time students. (Figure 4). The diagram shows the Total Number of Quiz Attempts per User for the full-time course compared to correspondence course in time. The horizontal axis indicates the start and end of the semester, the dates of the four graded tests of full-time students and the date of the graded test of correspondence students with a dashed line.

Comparing the aggregate self-testing data of correspondence and full-time students, full-time students quizzed more, their activities show a linear characteristic. Their activity is steady during the course, there are no typically ascending stages, while in the case of correspondence students, it can be observed that in the third half of the course period, they start quizzing more intensively, approaching the date of the only graded test. 


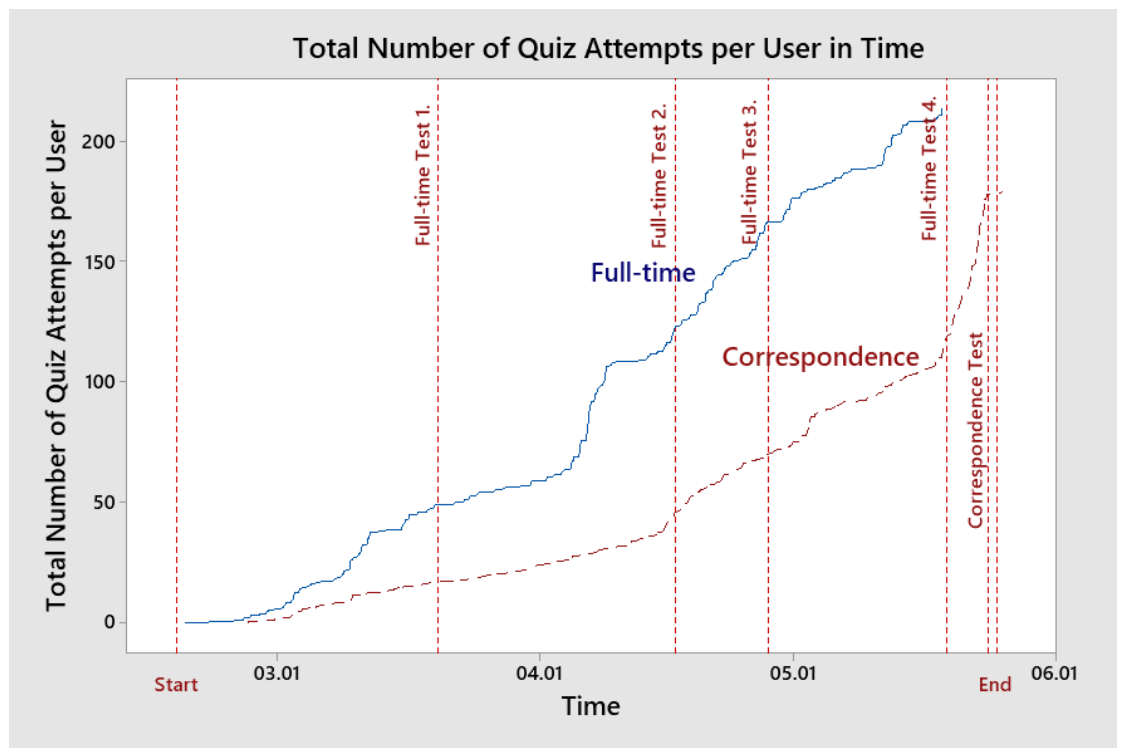

Fig. 4. Comparison of self-testing activities per student for full-time and correspondence courses in time

\subsection{Correlation between students' maximal quiz grades and their number of quizzing}

Full-time course: In Figure 5 the scatterplot of Sum of Max Grades versus the Total Number of Quiz Attempts can be seen. A quiz can be completed multiple times by a student with different efficiency. Of these, the best results (Max Grades) were considered and summarized. The scatterplots in Figure 5 show the sum of the best results of the three groups of students (Excellent, Satisfactory, Failed) versus the overall selftesting frequency. The horizontal axis shows the total attempts of the Learning the concept and Chapter review quizzes and the vertical axis shows the sum of the best grades achieved by the students on the quizzes. Thus, a given point in the scatterplot indicates the total number of times a given student has completed the quizzes and the result he has achieved on the quizzes. The regions of the panels in the Figure were divided into four quarters. A line was drawn along the horizontal axis at half the maximum number of quiz attempts and along the vertical line at half the maximum grades achieved on the quizzes. The region to the left of the vertical division is called Inactive, and the region to the right of it is called Active, referring to students' activity on quizzes. The region under the horizontal division was named Unsuccessful, the region above it was named Successful, referring to the results achieved by the students on the quizzes. 


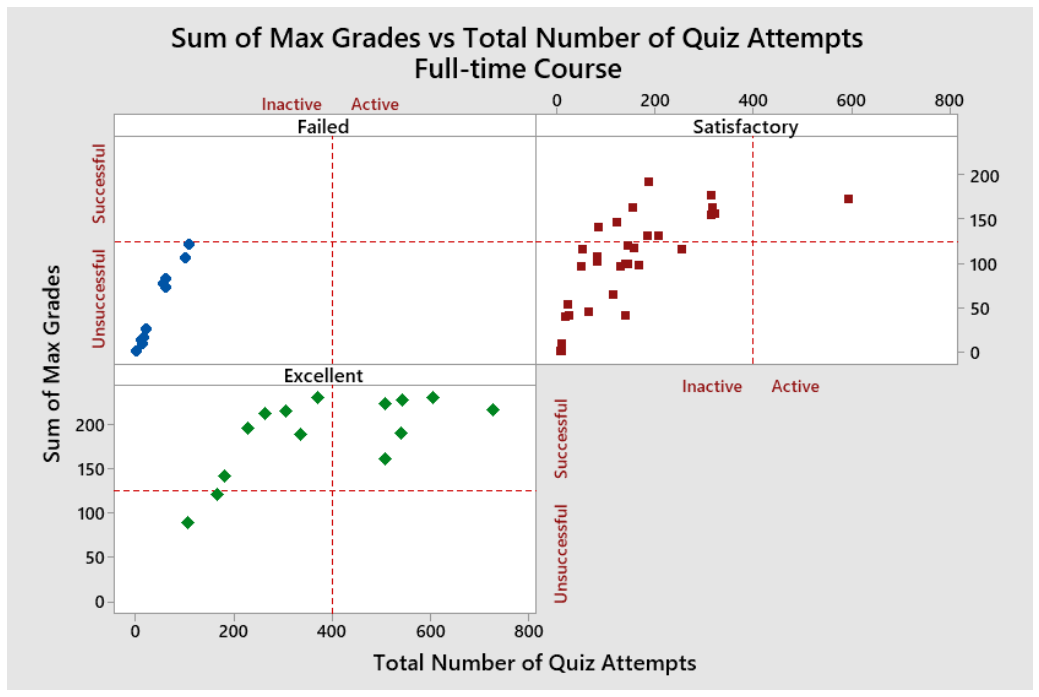

Fig. 5. The Total Number of Quiz Attempts and Sum of Max Grades of different groups of full-time students

Based on this, the individual quarters are marked: Inactive-Unsuccessful, ActiveUnsuccessful, Inactive-Successful and Active-Successful. (Table 1).

Table 1. Student classification based on activity and success

\begin{tabular}{|l|l|l|}
\hline Successful & Inactive-Successful & Active-Successful \\
\hline Unsuccessful & Inactive-Unsuccessful & Active-Unsuccessful \\
\hline & Inactive & Active \\
\hline
\end{tabular}

The Inactive-Unsuccessful quarter includes students whom self-testing activity were low and achieved low grades on quizzes. The Inactive-Successful quarter marks students whom self-testing activity were low, but their overall quiz grades are good. The Active-Unsuccessful quarter includes students in a group who, although quizzed extensively, still did not achieve high grades. Finally, the Active-Successful quarter groups together students who have quizzed a lot and their overall grades have been outstanding.

Without exception the members of the Failed group belong to the InactiveUnsuccessful quarter. They are not active in quizzing and their grades are low. Even the students with the best results in this group quizzed only about 100 cases in total. However, it appears clearly that those who quizzed more achieved better results than those who rarely.

A group of students whose members met the requirements but did not deliver outstanding performance (Satisfactory) were already more willing to quiz during the semester. Although members of this group also belong, almost without exception, to one of the Inactive quarters. That is, like members of the Failed group, they quizzed relatively little, but their average grades are better. Many of them belong to the Inac- 
tive-Successful quarter. Their grades show the largest scatter, with nearly the same attempt number their grades are quite varied.

Most of the members of the Excellent group belong to the Active-Successful quarter. They quizzed a lot and their grades on the quizzes are the best. Even the student who quizzed the least has quizzed at least 100 times, and many of them have a Max Grade above 500. Their best results are close to the maximum score they can get. However, there are some students in the Excellent Inactive-Unsuccessful quarter who have quizzed a little and have low Max Grades. They were also able to master the learning materials using videos or other documents, thus completing the course with excellent grades.

There are no students belonged to the fourth, Active-Unsuccessful quarter, suggesting that the self-testing activity was conscious. It is probable that the processing of test questions and the analysis of incorrect answers greatly contributed to the increase of grades.

Correspondence course: Almost the same is true for correspondence students. They can also be characterized by the correlation between their Total Number of Quiz Attempts and their Max Grades achieved like full-time students (Figures 6.). Unsuccessful students quizzed little, Successful students quizzed a lot. The Max Grades of the students belonging to the Satisfactory group are the most scattered. Some students who belong to the Active-Unsuccessful quarter appear here. This may not indicate a conscious quizzing activity, i.e., the tests were often completed, but no effort was made to provide or analyze the correct answers. Based on their activity, it seems as if they were just trying blindly.

There does not appear to be a significant difference between similar groups of fulltime and correspondence students in the trend of correlation between the Total Number of Quiz Attempts and the Maximum Grades achieved.

Within a topic: It further nuances the picture when we examine the activity related to self-checking tests within a specific topic (Figures 7.). The STAT-07 Chapter (statistical hypotheses testing) is perhaps the most complex topic within the subject. Here the majority of Failed students did not pay much attention to the quizzes. Most of them belong to the Inactive-Unsuccessful quarter, only one Failed student achieved good Max Grades on this specific topic. Students in the Satisfactory group typically belong to the Inactive quarters, and the scatter in their results is also large. There are students who quizzed a lot, completing the tests more than 100 times within the topic, with very low grades. It is questionable whether this learning strategy has any benefit. Excellent students quizzed a lot and consciously, quickly approaching the maximum grades on the tests. 


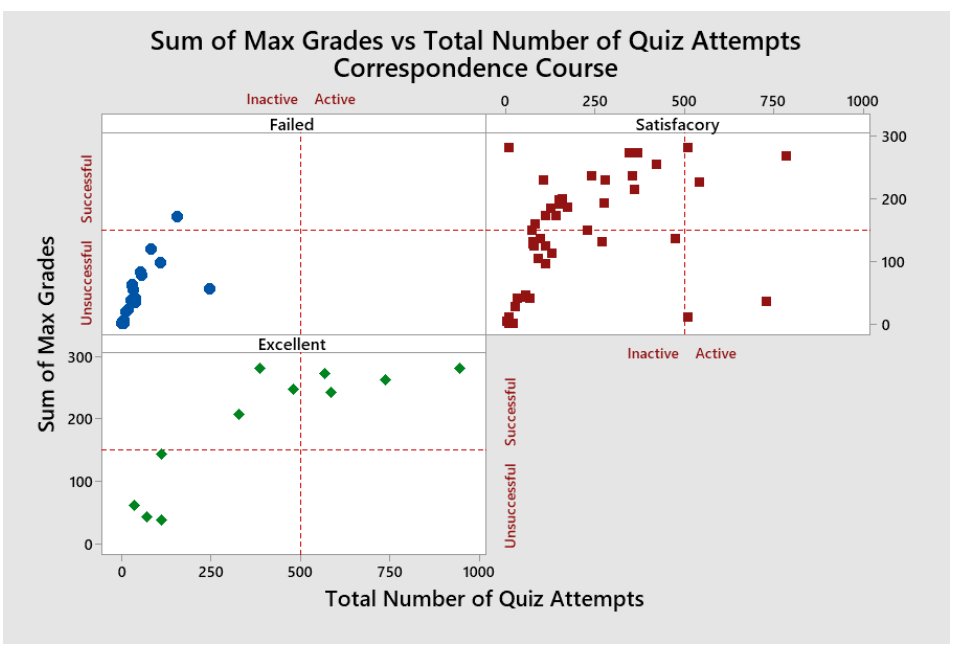

Fig. 6. The Total Number of Quiz Attempts and Sum of Max Grades of different groups of correspondence students

It can be stated, beneficial effects of self-testing can be observed not only in terms of the results of the whole course, but within each topic. This finding also highlights the importance of continuous learning. It confirms the assumption that the result of an individual, having any abilities, will be much better if using the possibility of selfquizzing and self-reflection. The time and energy invested in the exercise is reflected in the results achieved at the end of the learning period.

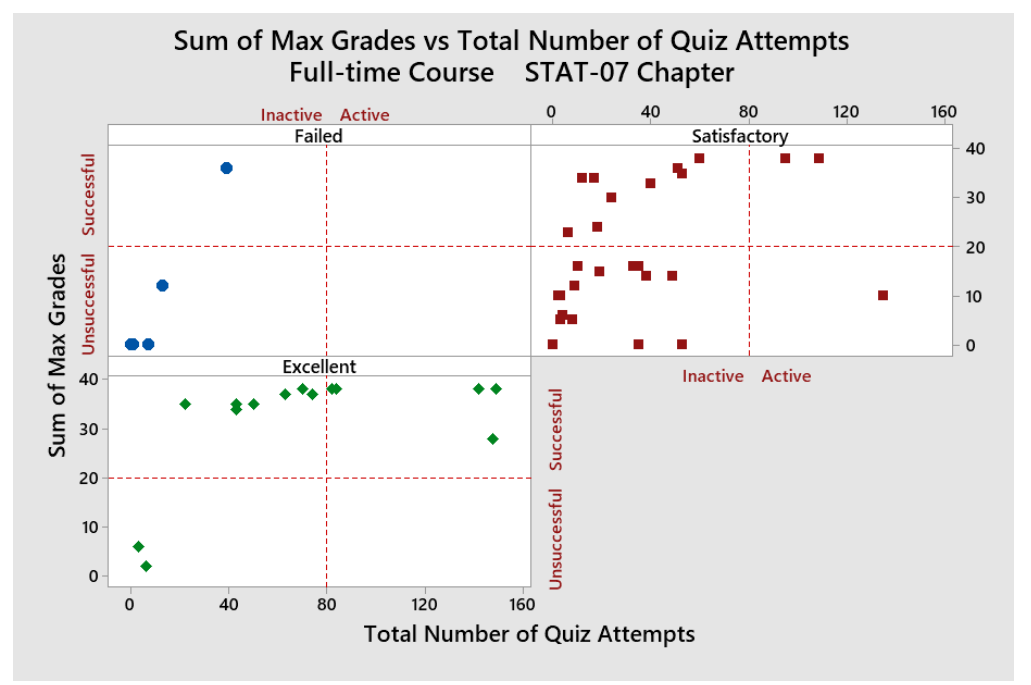

Fig. 7. The Total Number of Quiz Attempts and Sum of Max Grades of different groups of full-time students for a specific learning topic 


\subsection{Relationship between the Total Number of Quiz Attempts and the Total Score}

Full-time course: The scatterplot in Figure 8 shows the relationship between students' Total Score and their Total Number of Quiz Attempts. As the number of attempts increases, the scores achieved improve sharply. The minimal Total Score of 70 to pass the course is achieved in 100 - 150 attempts by most students. However, as the number of attempts increases, the scores no longer improve so dynamically. Between 150 and 300 attempts, there is little improvement, and above 300 attempts, there is no improvement at all.

The Total Score, of course, does not increase linearly with the Total Number of Quiz Attempts, but that the desired good result is increasingly approachable through diligent practice.

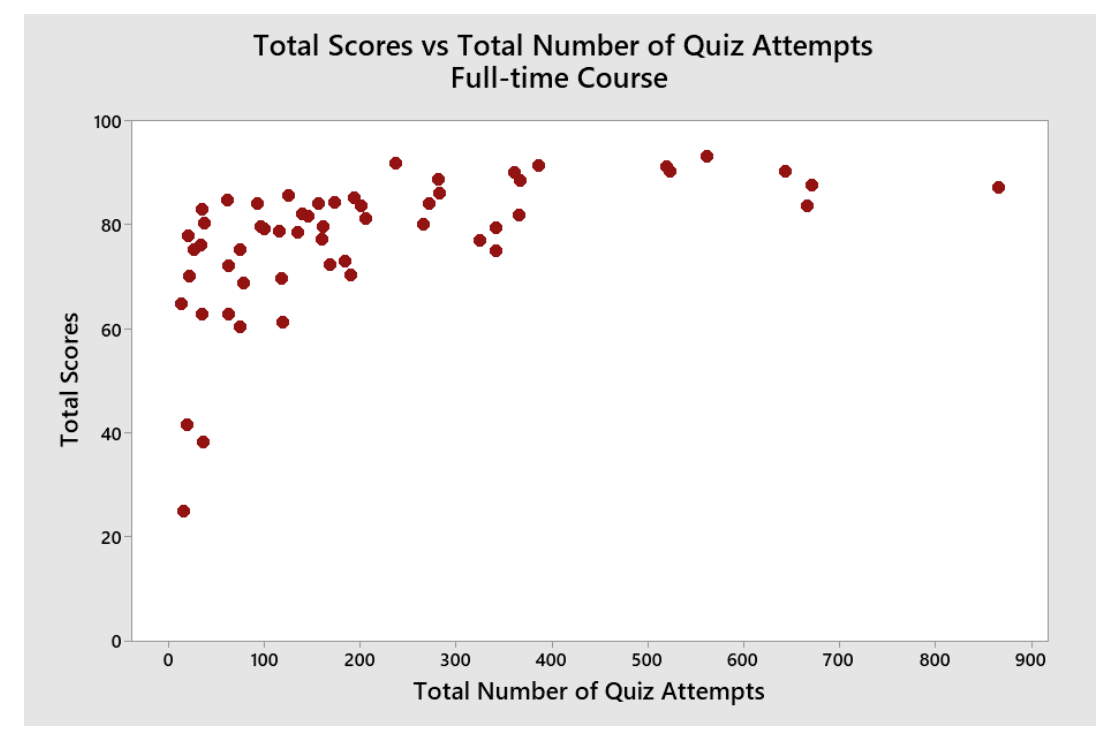

Fig. 8. Correlation between the Total Number of Quiz Attempts and the Total Scores for full-time students

Comparison the tendencies for full-time and correspondence students: In Figure 9, the red dots indicate full-time students, and the blue dots denote correspondence students. The scatter of the set of points representing full-time and correspondence students shows a different pattern. Most full-time students who completed the quizzes 100 to 150 times achieved the 70 points required to complete the course. There are also many correspondence students who reached the threshold at this number of attempts, but there are many who, despite the large number of attempts above 500 , not. The difference is probably since the time spent on learning, understanding, and deepening was used differently. 


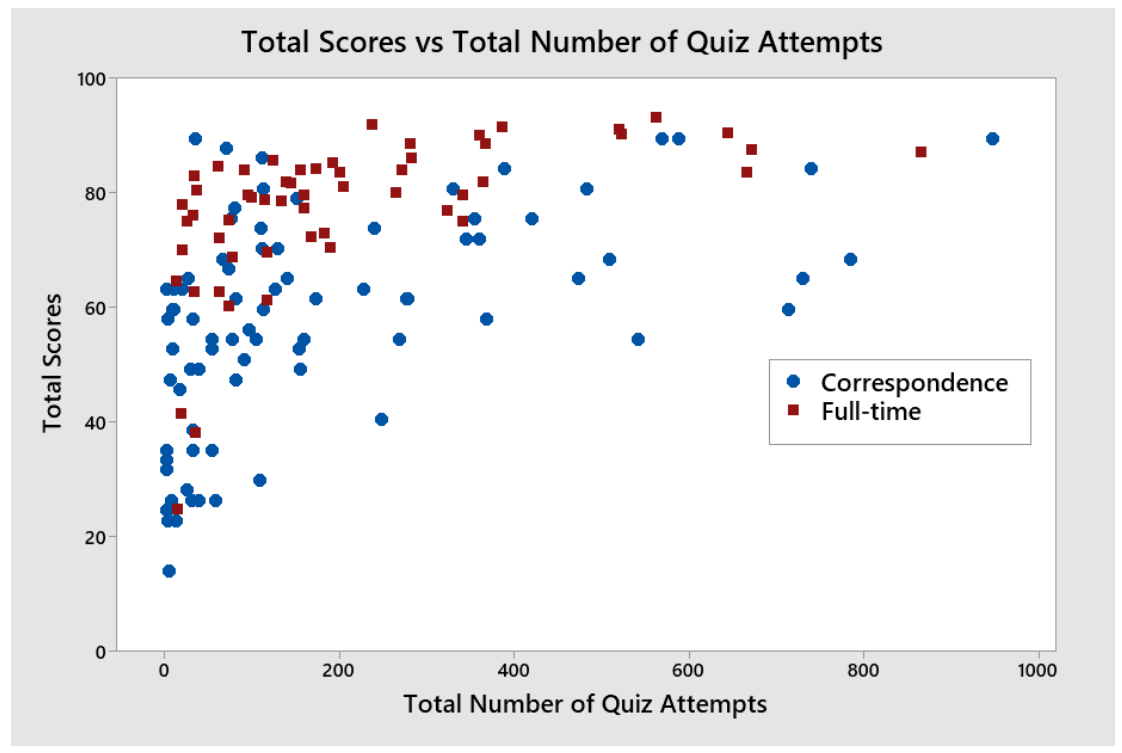

Fig. 9. Correlation between the Total Number of Quiz Attempts and the Total Scores for full-time and correspondence students

\subsection{Impact of learning resources on effectiveness}

We analyzed how the use of different learning resources in each topic affects the success, namely which success category (Failed, Satisfactory, Excellent) a student belongs to. Taking some examples, the "Predictors" indicating the use of the different learning resources are denoted as follows:

- QM4 (Quiz Maximum Grade 4) maximum grade in the quizzes in Topic 4

- QA3 (Quiz Attempts 3) the number of attempts related to the quizzes in Topic 3

- P1 (PDF 1) the number of views of PDF documents in Topic 1

- M7 (Minitab 7) the number of views of Minitab videos in Topic 7

- B6 (Book 6) the number of views of the exercise books in Topic 6

- V4 (Video 4) the number of video views in Topic 4.

Figure 10 shows the Scores values indicating the weights of each Predictor provided by the algorithm of the Matlab program using chi-square tests. (MATLAB 2008, release 2018b). It is clear that the Learning the concept quizzes and Chapter Review quizzes have a prominent role in terms of success compared to other learning resources. The first 6 learning resources determining student success were quizzes. Moreover, in terms of importance, the impact of learning resources on achievement, quizzes are at the top of the first third of the list. Among them were only some lecture notes (P1, P4), Minitab video (M7) and some exercise books (B6, B1). The most impact on success were the quizzes of topics $3,4,5$, the least impact on success were 
the exercise books of topics 1, 2, 3, 4. Moderately effective learning resources were videos of topics 2 and 3, and some Minitab videos.

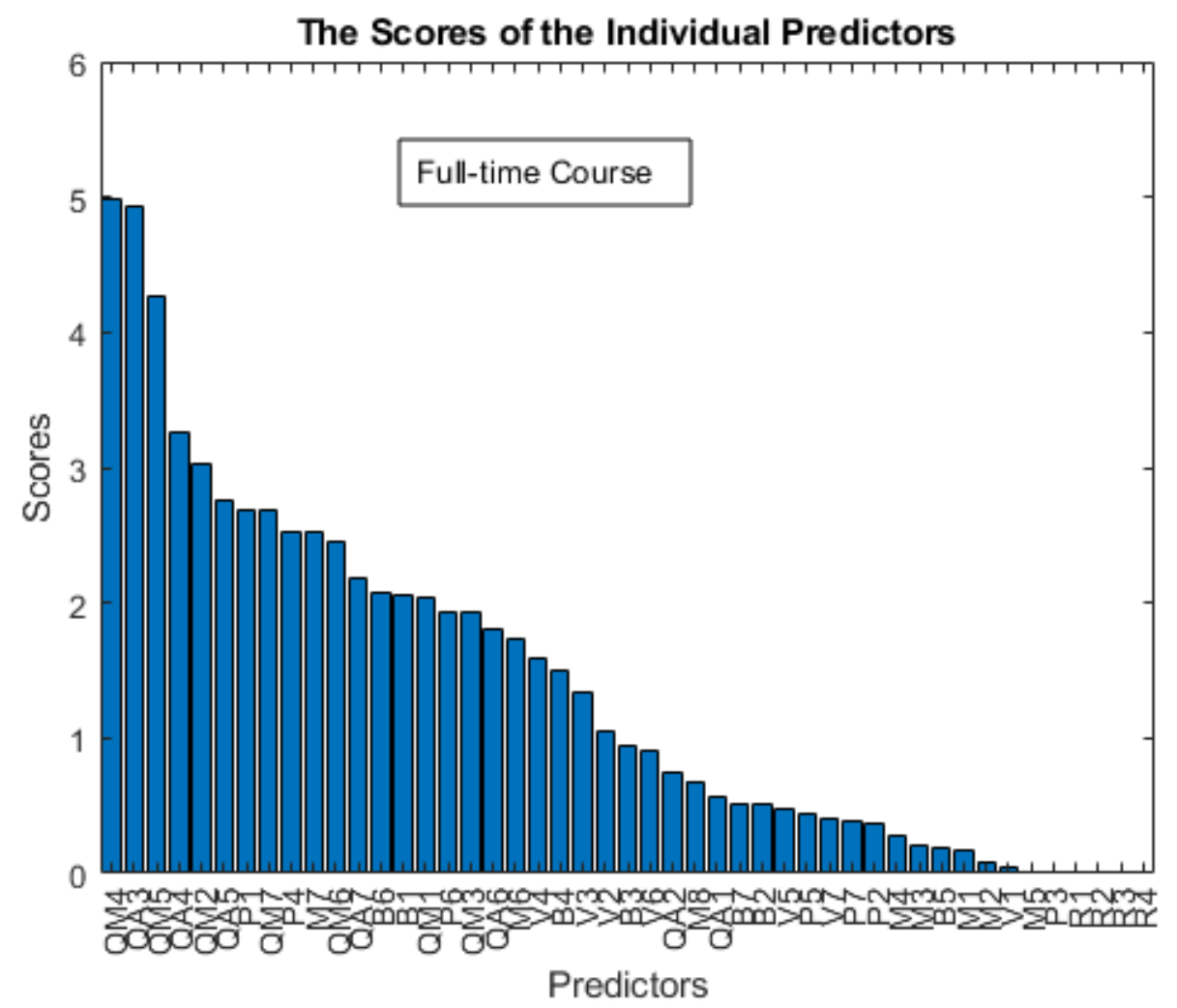

Fig. 10. The order of importance of the different learning resources in the full-time course

Findings for correspondence students were similar (Figures 11.). Quizzes have the greatest impact on effectiveness, these learning resources are typically at the top of the list, with high Scores. The location of books of exercises and PDF documents is highly scattered, some have moderate and some have almost no effect on performance. 
The Scores of the Individual Predictors

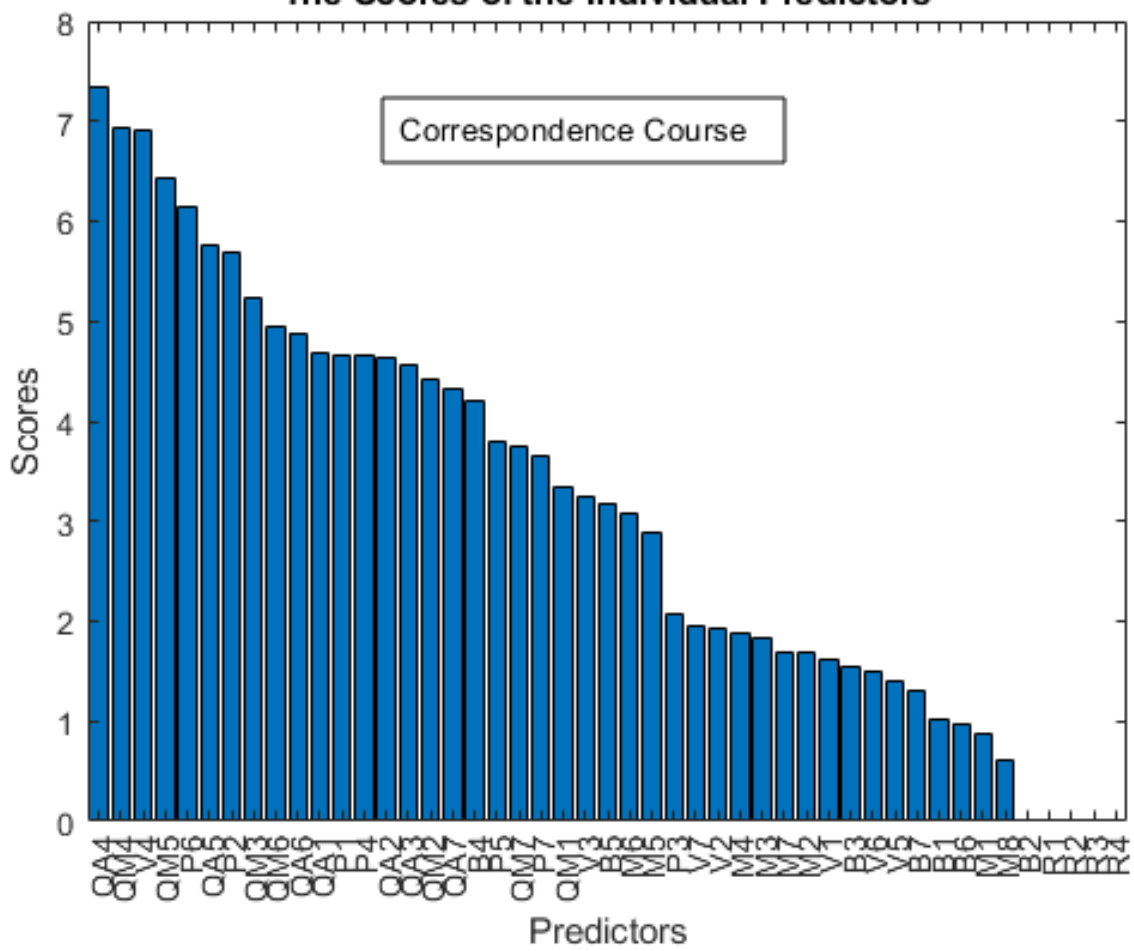

Fig. 11. The order of importance of the different learning resources in the correspondence course

It should be noted that in the study, we did not address the way the materials were used or the individual learning habits of the students. That is, we did not examine whether the student downloaded each material and studied it or opened it each time they had entered the online course.

\subsection{Quizzing and other activities}

Activities of full-time students: Figure 12 shows the Total Number of Views of Lecture Notes, Figure 13 shows the Total Number of Video Views, and Figure 14 shows the Total Number of Views of Books in relation to the Total Number of Quiz Attempts. The results suggest that members of the Failed group primarily choose nonquiz-type learning resources as the source of learning. They view Lecture notes, Videos, Books relatively more than they attempt quizzes. In contrast, students in the Satisfactory and Excellent groups view the different types of learning resources to a lesser extent. Although the results are quite scattered, it can be stated that the rate of selftesting is more common for Excellent students compared to other activities. 
Total Number of Lecture Notes Views vs Total Number of Quiz Attempts Full-time Course

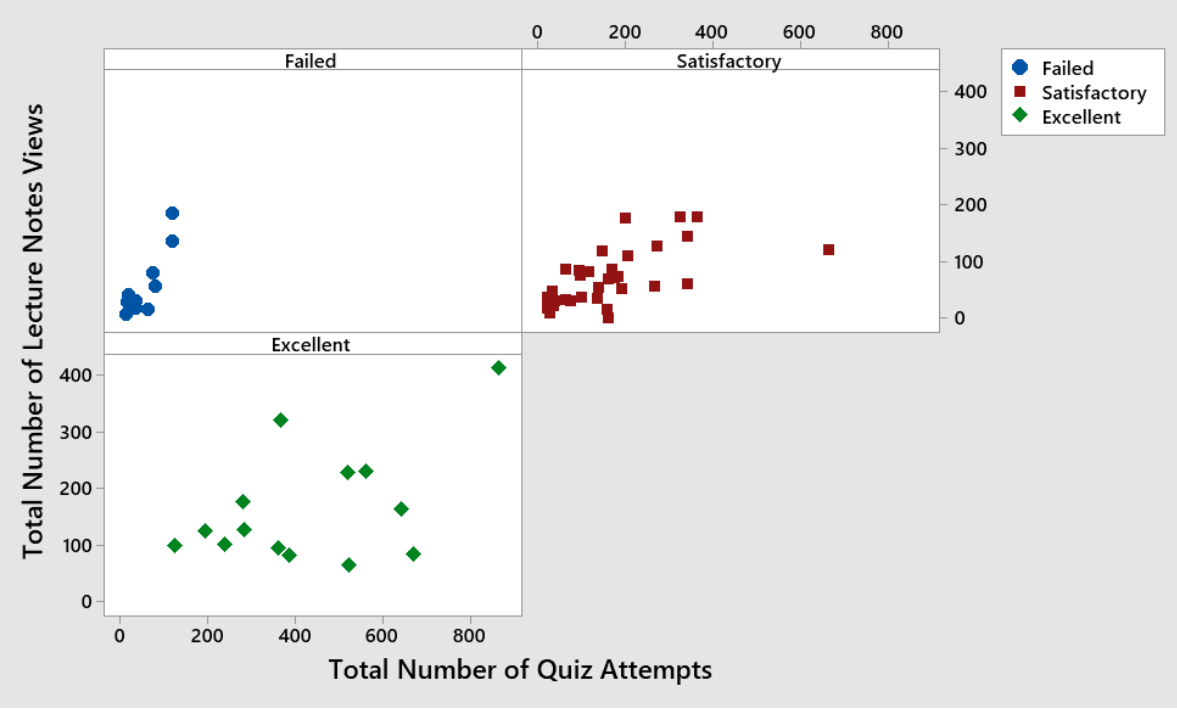

Fig. 12. Total Number of Quiz Attempts and Total Number of Lecture Notes for different groups of full-time students

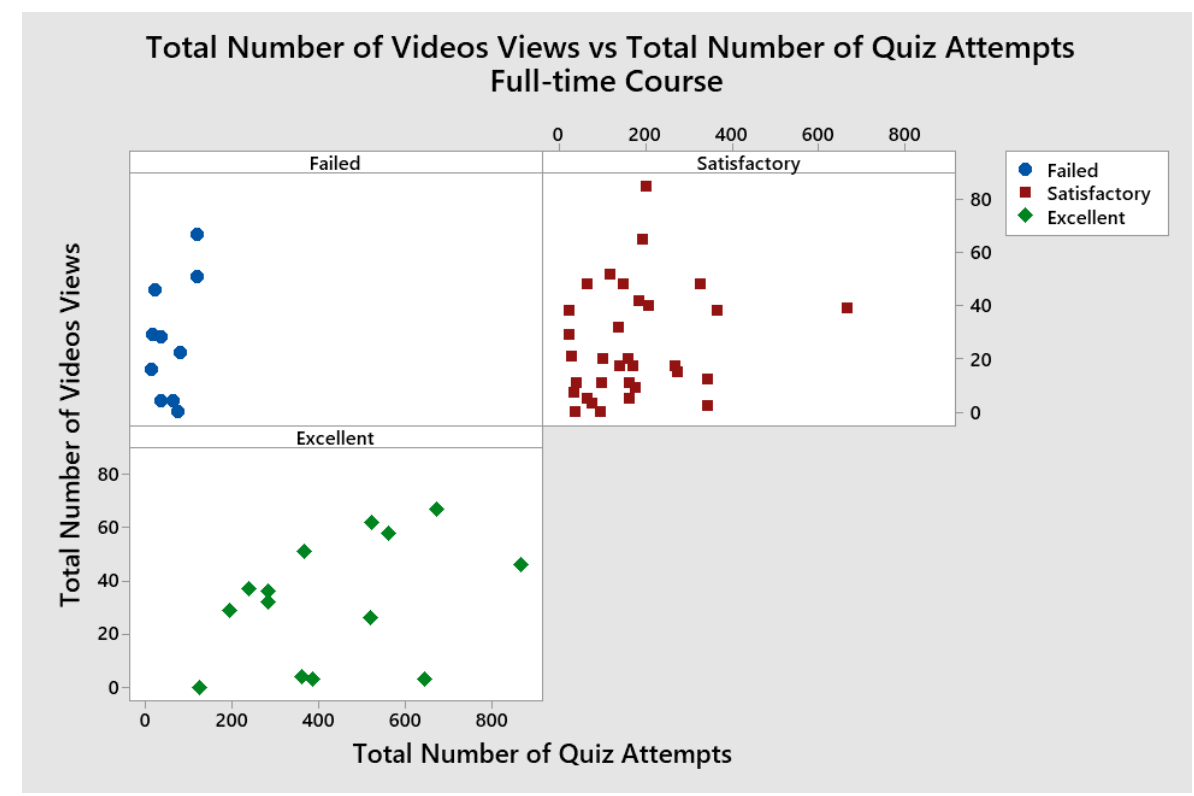

Fig. 13. Total Number of Quiz Attempts and Total Number of Video Views for different groups of full-time students 


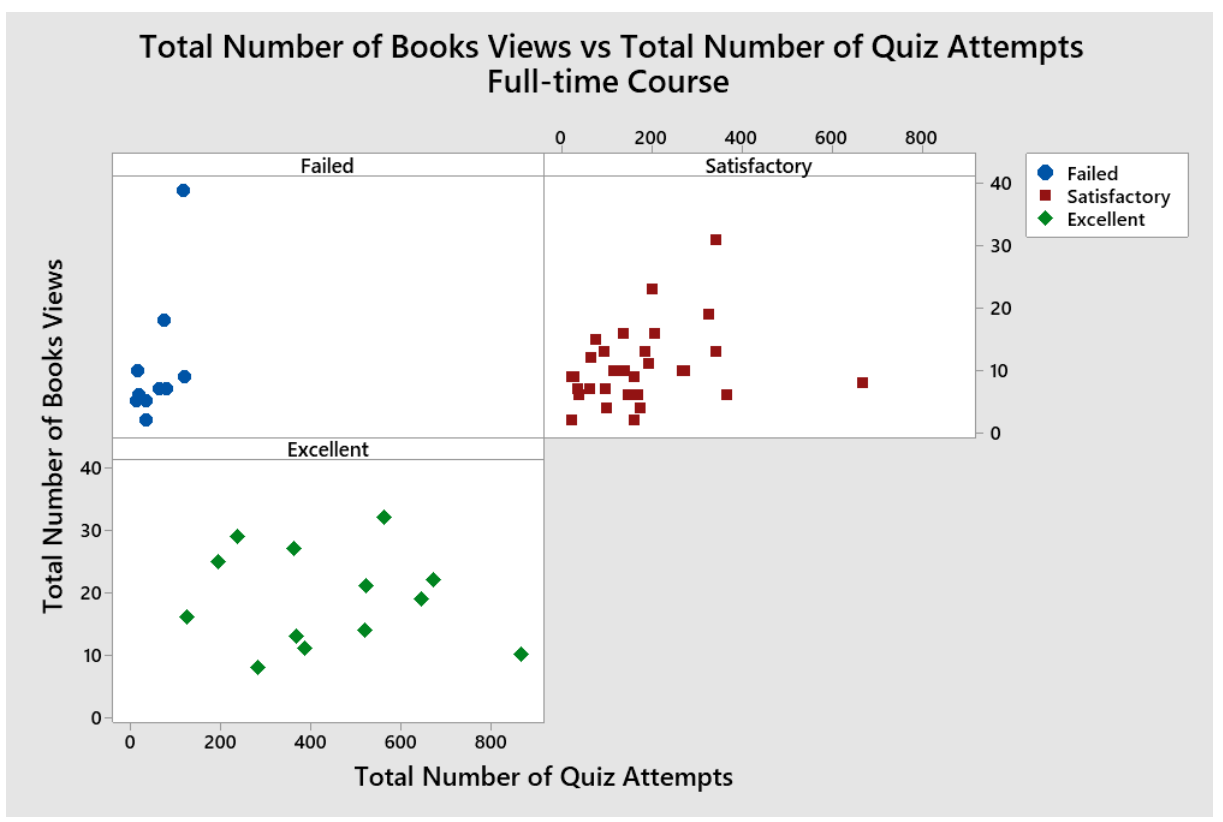

Fig. 14. Total Number of Quiz Attempts and Total Number of Books Views for different groups of full-time students

Activities of correspondence students: The scatterplot for correspondence students shows large variability for all three groups, but characteristics can also be detected here (Figures 15, 16 and 17.). The patterns suggest that members of the Failed and Satisfactory groups equally prefer different types of learning resources. The activity of students belonging to the Satisfactory and Excellent groups is much higher for all types of learning resources than of the members of the Failed group. Members of the Excellent group seem to be quizzing relatively more. For them the numbers of quiz attempts is higher than the number of views of other learning resources. Students who diligently quiz will be more successful by the end of the learning process. 


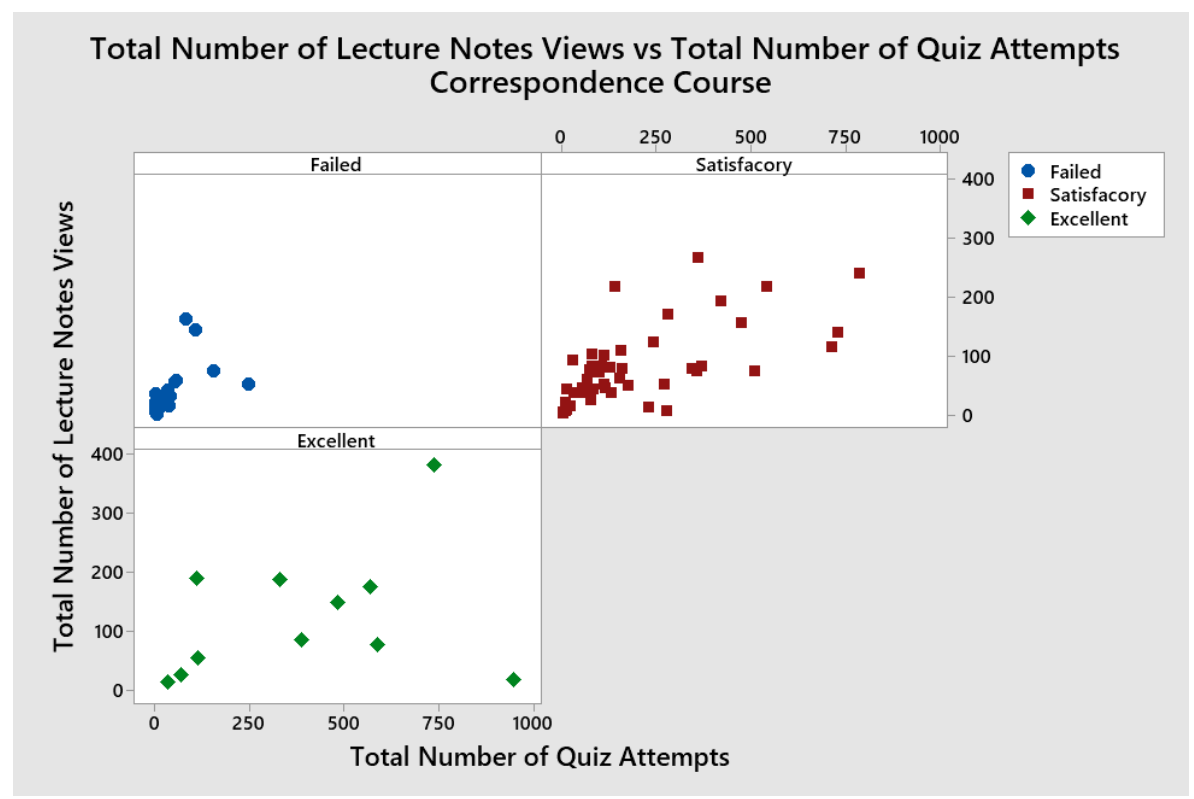

Fig. 15. Total Number of Quiz Attempts and Total Number of Lecture Notes Views for different groups of correspondence students

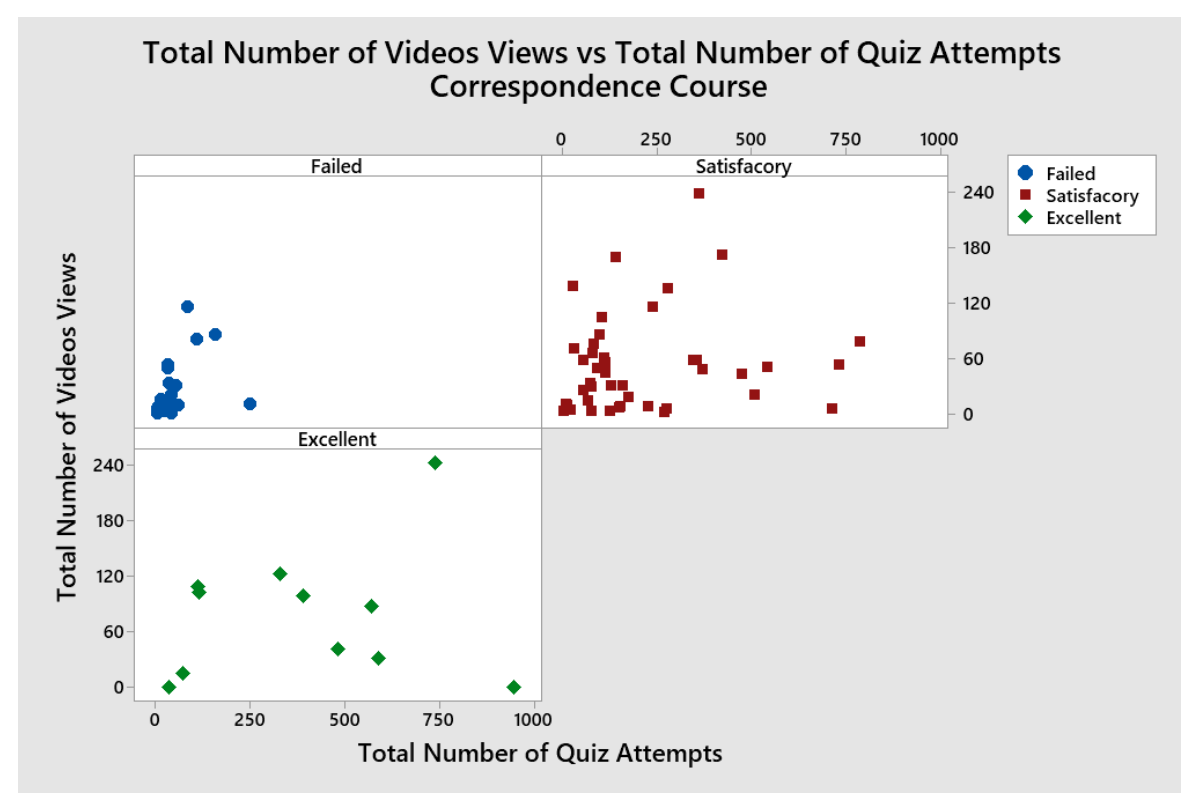

Fig. 16. Total Number of Quiz Attempts and Total Number of Video Views for different groups of correspondence students 


\section{$4 \quad$ References}

[1] Alavi, M., Marakas, G. M., Yoo, Y. (2002). A comparative study of distributed learning environments on learning outcomes. Information Systems Research, 13(4), 404-415. https://doi.org/10.1287/isre.13.4.404.72

[2] Anderson, T. (Ed.). (2008). The theory and practice of online learning. Athabasca University Press.

[3] Arbaugh, J. B. (2001). How instructor immediacy behaviors affect student satisfaction and learning in web-based courses. Business Communication Quarterly, 64(4), 42-54. https:// doi.org/10.1177/108056990106400405

[4] Arbaugh, J. B. (2002). Managing the on-line classroom: A study of technological and behavioral characteristics of web-based MBA courses. The Journal of High Technology Management Research, 13(2), 203-223.

[5] Blum, K. D. (1999). Gender differences in asynchronous learning in higher education: Learning styles, participation barriers and communication patterns. Journal of asynchronous learning networks, 3(1), 46-66.

[6] Bognár, L., Fauszt, T. (2020, September). Different learning predictors and their effects for Moodle Machine Learning models. In 2020 11th IEEE International Conference on Cognitive Infocommunications (CogInfoCom) (pp. 000405-000410). IEEE. https://doi.org/ $\underline{10.1109 / \operatorname{coginfocom} 50765.2020 .9237894}$

[7] Bognár, L., Fauszt, T. Nagy. G., Zs., (2021). Under Press, Analysis of Conditions for Reliable Predictions by Moodle Machine Learning Models. International Journal of Emerging Technologies in Learning. Vol. 16, No. 06. https://doi.org/10.3991/ijet.v16i06. $\underline{18347}$

[8] Bouhnik, D., Marcus, T. (2006). Interaction in distance-learning courses. Journal of the American Society for Information Science and Technology, 57(3), 299-305. https://doi. org/10.1002/asi.20277

[9] Butler, A. C., Karpicke, J. D., Roediger III, H. L. (2007). The effect of type and timing of feedback on learning from multiple-choice tests. Journal of Experimental Psychology: Applied, 13(4), 273. https://doi.org/10.1037/e527352012-769

[10] Chou, S. W., Liu, C. H. (2005). Learning effectiveness in a Web-based virtual learning environment: a learner control perspective. Journal of computer assisted learning, 21(1), 6576. https://doi.org/10.1111/j.1365-2729.2005.00114.x

[11] Choy, S., McNickle, C., Clayton, B. (2001). Online Support for VET Clients: Expectations and Experiences.

[12] Dutton, J., Dutton, M., Perry, J. (2002). How do online students differ from lecture students. Journal of asynchronous learning networks, 6(1), 1-20. https://doi.org/10.24059/ olj.v6i1.1869

[13] Fredericksen, E., Swan, K., Pelz, W., Pickett, A., Shea, P. (1999). Student satisfaction and perceived learning with online courses-principles and examples from the SUNY learning network. https://doi.org/10.24059/olj.v4i2.1899

[14] Gordon, N. (2014). Flexible pedagogies: Technology-enhanced learning. The Higher Education Academy, 1-24. 
[15] Hong, K. S. (2002). Relationships between students' and instructional variables with satisfaction and learning from a Web-based course. The Internet and Higher Education, 5(3), 267-281. https://doi.org/10.1016/s1096-7516(02)00105-7

[16] Liaw, S. S. (2008). Investigating students' perceived satisfaction, behavioral intention, and effectiveness of e-learning: A case study of the Blackboard system. Computers education, 51(2), 864-873. https://doi.org/10.1016/j.compedu.2007.09.005

[17] Liaw, S. S., Huang, H. M., Chen, G. D. (2007). An activity-theoretical approach to investigate learners' factors toward e-learning systems. Computers in Human Behavior, 23(4), 1906-1920. https://doi.org/10.1016/j.chb.2006.02.002

[18] M. Burns, (2018). 15 benefits of computer-based testing, Available: https://elearningindustry.com/15-benefits-of-computer-based-testing

[19] Marks, R. B., Sibley, S. D., Arbaugh, J. B. (2005). A structural equation model of predictors for effective online learning. Journal of management education, 29(4), 531-563. https://doi.org/10.1177/1052562904271199

[20] Martínez-Caro, E. (2011). Factors affecting effectiveness in e-learning: An analysis in production management courses. Computer Applications in Engineering Education, 19(3), 572-581. https://doi.org/10.1002/cae.20337

[21] Monllaó, Olivé, D., Huynh, D. Q., Reynolds, M., Dougiamas, M., Wiese, D. (2018, October). A supervised learning framework for learning management systems. In Proceedings of the First International Conference on Data Science, E-Learning and Information Systems (pp. 1-8). https://doi.org/10.1145/3279996.3280014

[22] Onah, D. F., Sinclair, J., Boyatt, R. (2014). Dropout rates of massive open online courses: behavioural patterns. EDULEARN14 proceedings, 1, 5825-5834.

[23] Roediger III, H. L., Putnam, A. L., Smith, M. A. (2011). Ten benefits of testing and their applications to educational practice. Psychology of learning and motivation, 55, 1-36. https://doi.org/10.1016/b978-0-12-387691-1.00001-6

[24] Rowland, C. A. (2014). The effect of testing versus restudy on retention: a meta-analytic review of the testing effect. Psychological Bulletin, 140(6), 1432. https://doi.org/10.1037/ a0037559

[25] Sanders, D. W., Morrison-Shetlar, A. I. (2001). Student attitudes toward web-enhanced instruction in an introductory biology course. Journal of Research on computing in Education, 33(3), 251-262. https://doi.org/10.1080/08886504.2001.10782313

[26] Selim, H. M. (2007). Critical success factors for e-learning acceptance: Confirmatory factor models. Computers \& education, 49(2), 396-413. https://doi.org/10.1016/j.comp edu.2005.09.004

[27] Shukor, N. A., Abdullah, Z. (2019). Using learning analytics to improve MOOC instructional design. International Journal of Emerging Technologies in Learning (iJET), 14(24), 6-17. https://doi.org/10.3991/ijet.v14i24.12185

[28] Tan, M., Shao, P. (2015). Prediction of student dropout in e-Learning program through the use of machine learning method. International Journal of Emerging Technologies in Learning, 10(1). https://doi.org/10.3991/ijet.v10i1.4189 


\section{Authors}

László Bognár is the professor of Applied Statistics at the University of Dunaújváros, Táncsics M. u. 1. Dunaújváros, Hungary H-2400, www.uniduna.hu. He also works for APAVE Hungary and holds trainings in different fields of industrial statistics, www.apave.hu. E-mail bognar.laszlo@uniduna.hu

Tibor Fauszt is the associate professor of Information Technology at the Budapest Business School University of Applied Sciences. Buzogány u. 10-12. Budapest, Hungary, H-1149. https://uni-bge.hu/en. He is a member of the Informatics Sciences Committee of the Hungarian Rectors' Conference. http://www.mrk.hu/bizottsagok/ informatikai-tudomanyok-bizottsaga/

Mariann Váraljai is the associate professor of Information Technology at the University of Dunaújváros - Institute of Informatics - Department of Software Development and Application, Táncsics M. u. 1. Dunaújváros, Hungary H-2400, www.uniduna.hu. varaljai.mariann@uniduna.hu

Article submitted 2021-02-02. Resubmitted 2021-03-05. Final acceptance 2021-03-06. Final version published as submitted by the authors. 